\title{
Arte e Infância: inspirações para novos possíveis em tempos de pandemia
}

Carmem Lúcia Sussel Mariano ${ }^{1}$

Renata Lopes Costa Prado²

Renato Noguera ${ }^{3}$

Recebido em: 15/12/2020

Aprovado em: 16/12/2020

DOI: $10.5965 / 23580925242020006$

1 Doutora em Psicologia Escolar pela Universidade de São Paulo (IP/USP). Professora da Universidade Federal Fluminense, campus de Angra dos Reis-RJ.

2 Doutora em Psicologia Social pela Pontifícia Universidade Católica de São Paulo (PUC/SP). Professora da Universidade Federal de Mato Grosso, campus de Rondonópolis-MT.

3 Doutor em Filosofia pela Universidade Federal do Rio de Janeiro (UFRJ). Professor da Universidade Federal Rural do Rio de Janeiro (UFRRJ). 
Neste ano marcado, mundialmente, por uma pandemia e, nacionalmente, por decisões governamentais que tendem a aprofundar desigualdades e a desmantelar políticas públicas, assistimos a intensificação de problemas sociais há muito denunciados por pesquisas acadêmicas e pelos movimentos sociais. Conclusões acerca dos efeitos da pandemia no contexto brasileiro são prematuras, pois estamos ainda imersos nela: no dia de hoje (14 de dezembro), 27.419 novos casos de infecção pelo novo corona vírus e 520 mortes foram registrados. Mesmo considerando os limites das análises pela falta de distanciamento temporal, há observações a serem feitas no que tange à retração do mercado de trabalho, à sobrecarga de trabalho que recaiu sobre as mulheres, ao aumento da pobreza, da violência doméstica, de agravos à saúde mental, de dificuldade de acesso à educação escolar e de vulnerabilidade social comparativamente maior entre pessoas indígenas, negras e de origem periférica. Vale lembrar que tivemos o emblemático homicídio de João Alberto Freitas, o Beto, um homem negro de 40 anos, num supermercado Carrefour em Porto Alegre - RS na véspera do dia da Consciência Negra que não teve por parte da imprensa brasileira a mesma cobertura que o assassinato de George Floyd nos Estados Unidos da América alguns meses antes. O que dizer do sistemático assassinato de crianças negras? O que dizer da necroinfância (NOGUERA, 2020)? Não podemos deixar de destacar que no Estado do Rio de Janeiro até o início de dezembro foram doze mortes por "balas perdidas", o detalhe: todas as crianças mortas eram negras.

Esses temas têm estado em pauta na mídia e em outras arenas, mas raramente as discussões focalizam os impactos sobre as crianças, que de maneira geral são tratadas como se vivessem em um mundo à parte, especial e supostamente protegido. No entanto, como argumenta Qvortrup (2011, p. 207), "a infância é, em princípio, exposta (econômica e institucionalmente) às mesmas forças sociais que os adultos, embora de modo particular [...]". No contexto de pandemia, elas são atingidas pela perda da renda familiar; são, muitas vezes, vítimas da violência dentro de casa; sentem a ausência de seus pares, professores 
e avós; lidam como enclausuramento e as limitações de seus espaços e movimentos corporais; enfrentam as dificuldades de um ensino remoto; vivenciam o luto e o medo da doença; aprendem também; e descobrem, talvez, novas alegrias.

As expressões artísticas constituem dimensão fundamental do humano e nos acompanham desde a pré-história. O modo como nos relacionamos com elas, no entanto, se transforma ao longo do tempo e apresenta especificidades características nos diferentes contextos sócio históricos. Que especificidades na relação entre arte e infância podem ser vislumbradas no atual contexto pandêmico?

Para refletir sobre essa questão, outras perguntas se impõem e foram elas que nos instigaram a propor o presente dossiê. Quais possíveis sentidos o consumo e a produção das artes veem adquirindo para as crianças em situação de confinamento? Enquanto muitas crianças estão "presas" em casa, a experiência artística é vivida como experiência de liberdade? Ou seria sentida como forma de apaziguamento e de ocupação do tempo livre? E os artistas, representam de outra maneira as crianças e a(s) infância(s) desse nosso tempo?

A articulação entre esses três termos - infância, arte e pandemia - pode ser pensada também à luz do que o líder indígena Ailton Krenak (2019) tem insistentemente nos alertado: é necessário encontrar um outro jeito de estar no mundo e precisaremos para isso de muita imaginação. A pandemia, assim como a emergência climática e as condições precárias de vida de grande parte da população mundial, nos mostra mais uma vez a urgência de pensar e construir novos possíveis. E, nessa direção, a articulação entre infância e arte nos parece profícua.

As artes, assim como as crianças, parecem não se acomodar bem na sociedade administrada, dotada de um amplo aparato de controle técnico-burocrático dos mais diversos aspectos da vida. Afinal, como afirma Cunha (2014, p. 76), a capacidade das crianças habitarem um "[...] tempo-espaço híbrido é, em nosso entendimento, onde as crianças se aproximam da arte, que também opera nesse trânsito entre a realidade e a fantasia".

Os artigos que compõem este dossiê trazem pistas para 
adensarmos nas reflexões sobre essas e outras questões.

Apesar de vivermos um tempo em que boa parte das crianças só pode ver o mundo a partir de suas janelas ou quintais, o artigo Transver o mundo: linguagens criativas de crianças em situação de confinamento, de Cristiana Callai, Greice Duarte de Brito Silva e Marta Nidia Varella Gomes Maia, nos convida a transver este espaço-tempo de confinamento pela ótica das expressões das crianças, de suas linguagens criativas e de seus "exercícios de ser criança" (Manuel de Barros) que amplificam as possibilidades, os afetos, as sensibilidades, as invenções e trazem a potência de mostrar e afirmar outras lógicas, mais interessadas no existir poético e na experiência sensível, que desmontam "nossa compreensão metrificada do viver".

Os desafios e possibilidades de realizar investigações com crianças em tempos de isolamento social são abordados no artigo: Como fazer pesquisa com crianças em tempos de pandemia? Perguntemos a elas. Luciana Hartmann, ao se ver impedida de realizar sua pesquisa de campo com crianças imigrantes em Lisboa, ante o fechamento das escolas devido à pandemia de Covid-19, enfrentou este desafio perguntando às próprias crianças sobre como fazê-lo. Assim, partindo de uma perspectiva ética e metodológica que assume a participação das crianças, de fato, como co-pesquisadoras, o artigo descreve o processo de elaboração coletiva, entre adultos e crianças, de um questionário direcionado a crianças que vivenciaram o isolamento social decorrente da pandemia. A partir de problematizações sobre nossas dificuldades epistemológicas de conciliar os interesses de pesquisa dos adultos e as demandas de investigação das crianças, Hartmann vai, passo a passo, partilhando o fazer de suas explorações com a colaboração das próprias crianças sobre as possíveis estratégias de investigação com este grupo etário em tempos de pandemia, evidenciando o lugar não menos importante de, ao lado de perguntas "técnicas", contemplar questões que instiguem a capacidade imaginativa e criativa, bem como perguntas que abrem possibilidades para a fabulação.

Os bebês, sujeitos geralmente invisibilizados em nossas sociedades ocidentais, foram o foco do artigo Bebês na arte vivi- 
da em casa: experimentando e (re) criando o cotidiano em tempos de pandemia, de Carla Jeniffer Rodrigues de Mendonça. A partir de dados coletados por meio de questionários respondidos via aplicativo de whatsapp por seis mães de bebês neste período de isolamento social, a autora aborda o cotidiano de bebês em tempos de pandemia de COVID-19 e suas experiências com/nas linguagens artísticas com seus familiares, como sujeitos ativos e potentes nas práticas culturais e artísticas, mostrando que, mesmo no cotidiano limitado e atarefado imposto às mães pelos isolamento social, os bebês, em suas múltiplas interações e intervenções, aprendem, improvisam e (re)criam, transformando o espaço doméstico e as relações, abrindo brechas para desmontar nosso olhar adultocêntrico que ignora a capacidade de agência dos bebês.

Os desafios da alfabetização em tempos em que as aulas presenciais foram suspensas e foi demandada uma rápida adaptação de professores, gestores e estudantes ao ensino remoto podem ser pensados a partir do texto Alfabetização em contexto de pandemia: algumas ideias sobre transcriação, de autoria Thamara Parteka e Elni Elisa Willms. As autoras discutem as implicações de uma alfabetização dissociada do letramento, tal qual proposições defendidas na Nova Política Nacional de Alfabetização de 2019, e, a partir do conceito de transcriação, apresentam a importância de práticas lúdicas e corpóreas nos processos de alfabetização, mesmo diante de cenários desafiadores como o do ensino não presencial.

Este dossiê traz, ainda, relatos de experiência de três diferentes contextos que abordam possibilidades de reinvenção de práticas e olhares ante a exigência de isolamento social decorrente da pandemia de Covid-19. Trazendo uma experiência de um espaço institucional como o de uma escola pública, Lara Tatiane Matos, no texto Pandemia e educação na escola pública: um relato possível e incompleto, nos fala sobre suas instigantes experimentações como professora de artes/teatro no ensino que precisou ser remoto. Sem deixar de mencionar os percalços, as dificuldades de conectividade com as crianças e suas famílias, os desconfortos entre o ideal e o possível neste tempo de pan- 
demia, a autora nos conduz a percorrermos um fazer docente pautado pela invenção, pelo constante instigar da criatividade e da criação por meio de perguntas que perpassam as atividades, bem como pelo cuidado e afeto com as crianças e suas famílias.

Caminhos inventados no campo do teatro no contexto de isolamento social também é o foco do relato de Charles Valadares Tomaz de Araújo, no texto Teatralidades para infâncias confinadas: jogos, narrativas e outras poéticas virtuais, que narra sobre a criação e execução de um experimento teatral tecno-vivial com crianças a partir do convívio virtual, bem como sobre as reflexões, nesse percurso, sobre uma prática que possibilite pensar os cotidianos da criança e uso inventivo das tecnologias de comunicação.

Em tempos de confinamento, a pergunta "O que você enxerga da sua janela?" é uma questão suficientemente mobilizadora e esta foi a pergunta disparadora de uma roda de conversa virtual com educadores sobre "imaginação e lúdico", relatada no texto O lúdico em tempos de (des)esperanças. Nesse texto, ao refletir sobre os lugares (ou não-lugares) do lúdico, Jonathan Aguiar nos convida a debater sobre a relevância do brincar e das atividades lúdico-criadoras no decorrer do período de pandemia, justamente por abrirem espaço para conectar-se com a vida e com o imaginar.

Em meio a esta crise sanitária e humanitária de grandes proporções, convidamos todas, todos e todes a percorrerem os artigos deste dossiê que trazem interlocuções entre arte, infância e as singularidades deste tempo. Sintam-se provocados a brincar, jogar, experenciar, criar, transcriar, (re)inventar práticas e caminhos, aprender a fazer perguntas, lutar, cuidar, imaginar, transver o mundo e conectar-se com a vida para que possamos resistir à pandemia de Covid-19 e a tudo que nos desumaniza. 


\section{REFERÊNCIAS}

CUNHA, Sandra Mara da. Eu canto para você: saberes musicais de professores da pequena infância. Tese (doutorado em Educação). USP, São Paulo, 2014.

KRENAK, Ailton. Ideias para adiar o fim do mundo. São Paulo: Companhia das Letras, 2019.

NOGUERA, Renato. Necroinfância: por que as crianças negras são assassinadas. In: Lunetas, 2020. Disponível em: https:// lunetas.com.br/necroinfancia-criancas-negras-assassinadas/. Acesso em 15/12/2020.

QVORTRUP, Jens. Nove teses sobre a "infância como um fenômeno social". Pro-Posições, Campinas, v. 22, n. 1, p. 199211, abr. 2011. 